\title{
Types and Forms of Evaluation at Primary School from the Viewpoint of Teachers
}

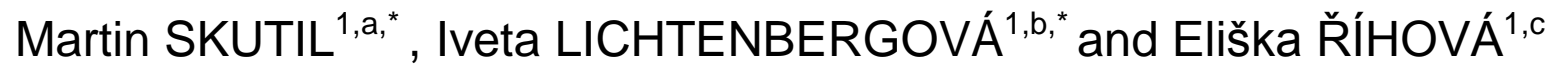 \\ ${ }^{1}$ Institute of Primary and Preprimary Education. Faculty of Education, University of Hradec \\ Králové, Rokitanského 62, 50003 Hradec Králové, Czech Republic \\ amartin.skutil@uhk.cz, biveta.lichtenbergova@uhk.cz, ${ }^{\mathrm{c}}$ eliska.rihova@uhk.cz \\ ${ }^{*}$ Corresponding author
}

Keywords: Primary education, evaluation, pupils' view

\begin{abstract}
In the context of overall changes in education and the search for new ways of working, there are also changes in the area of evaluation. It is manifested in the tendency for a comprehensive evaluation of a pupil, the tendency to draw a pupil into evaluation processes, the tendency to abolish the classification or at least equalise the classification and verbal evaluation. The aim of this paper, which is part of a broader survey, is to find which types and forms of evaluation are used in primary schools. Within the quantitative approach, a questionnaire of customised construction was administered, and this was answered by a total of 115 respondents. It turns out that quantitative forms of evaluation still prevail, but they're complemented by qualitative forms where formative evaluation types and self-evaluation predominate. From this it can be seen that the development of personality is increasingly accentuated within school education at the expense of simple expression of pupils' performance.
\end{abstract}

\section{Introduction}

Evaluation is an intellectually highly challenging skill that based on a subjective approach, allows a person to distinguish important phenomena from unimportant in the surrounding world and to distinguish good from bad among the important phenomena. Evaluation is inseparable from values, it's related to their awareness, discovery, highlighting, confirmation or questioning and criticising [1].

Processes in the evaluation manifestations are also permeated by cognitive and affective components. The evaluation definitely includes relationships, the preferred values of evaluators and evaluated individuals, the experiences and attitudes towards life and the moral-free features that are essentially formed from the birth by the family model of education and which can already be very different in superficial comparison. Also for this reason, we consider the evaluation to be a very complex activity in which it's not possible to be prepared and not informed by the basic information.

School evaluation is a very important part of a pupil's educational process and to a large extent it can influence them, and we have to bear-in-mind that we can influence both positively as well as negatively. Improperly set evaluation can affect a child's lifelong approach to education. School evaluation is an important part of quality education and also an important factor in communication between the teacher, the pupil and the pupil's parent. At present, there are various types and forms of evaluation used in Czech Republic primary schools. 


\section{Theoretical Basis}

At first glance it may appear that teachers' are the only main actors, but pupils are also part of the evaluation. Teacher and pupil co-operation in learning activities evaluation can only be included in an environment with a good social climate. The term "social climate" refers to the long-term phenomena typical for the given class and given teacher over several months or years. Their creators are: pupils of the whole class, groups of pupils in the given class, individual pupils, a set of teachers teaching in the class, and finally teachers as individuals. The class's social climate is affected by a wider social phenomenon such as the school's social climate and the social climate of teaching staff [2].

Průcha [3] argued that there are different views from experts on who is the source of climate formation in the classroom. Some think that the source is pupils, and others believe that it's the teacher who forms the classroom's climate. The above quote confirms my belief that both the pupils as well as the teachers are the important creators of a good social climate.

Slavík [1] distinguishes the internal and external teaching evaluators. The internal evaluators include teachers and pupils who have long been present in the teaching process. Conversely, external evaluators may be hospitable teachers, inspectors, principals and also a pupil's parents. Pupil assessment is generally considered to be one of the key teaching components and belongs to the learning objectives. Koláŕ and Šikulová [4] mention the so-called hidden evaluation that can take place in the classroom. It's an evaluation whereby the pupil evaluates the teacher, the quality of teaching, classmates and especially themselves. The teacher does not ask for this evaluation, nor do they force it, it happens spontaneously.

\section{Forms and Types of Evaluation}

There are many types and forms of evaluation as well as several divisions, but each one has its own reason and use. The teacher intentionally decides on the type of evaluation, with regard to a particular pupil, the intended work goal and the evaluation's consequences, etc. Many teachers have learned about several types of evaluation during their practice, but they may not know all of them. That's why I will now deal with the basic division according to various aspects.

We can distinguish two basic approaches to evaluation - quantitative and qualitative [4].

- Quantitative evaluation in Czech education is mainly represented by classification. The problem is that it's generalising information that usually doesn't take into account a variety of pupil characteristics, which reduces its prominent value. The mark is only a formal reflection of the expression of a very complex evaluation process. Other quantitative evaluation options include, for example, expression by a number of points that are often used in tests, percentage expressions, or counting good/bad answers.

- Qualitative evaluation is usually associated with verbal evaluation. The verbal evaluation shouldn't just contain information on the learning outcomes achieved but should also include the attitudes and efforts of pupils. Its advantage is that it can capture the individual progress of each pupil better and provide more solid information on strengths and weaknesses. Verbal evaluation can be used as both continuous as well as final. In addition to these positive aspects, verbal evaluation is demanding for teachers, there is a risk of slipping into the cliché or to use it as a re-telling of the mark. 
With regard to a number of different evaluation types, we mention the basic three, which generally occur in Czech schools:

- Formative evaluation. This concept occurred as early as the 1970 s, when experts dealt with the research of testing pupils' knowledge. It's also referred to as continuous evaluation and it's already evident that it's focused on the ongoing evaluation of pupils' educational progress. It allows pupils to have time for substance acquisition and follow-up learning. Feedback from teachers and pupils plays an important role [6]. Through teachers' feedback, pupils have an overview of their progress and lessons focused on their future performance. Teachers provide information that they can follow to meet a pupil's needs. This evaluation is based on a pupil's active participation in their learning process and the development of their "learn to learn" abilities. Starý and Laufková [6] mention that formative evaluation is the first step on the way to the pupil's autonomous evaluation and thanks to that the pupil can learn and later they can recognise for themselves what is good in their work, what to develop and what to improve.

- Summative evaluation, sometimes called a final evaluation, has the ultimate meaning to get a final overall view of a pupil's performance. It establishes the level of knowledge gained over a period of time and for example admission tests can be a typical example. Unlike formative evaluation, a summative evaluation doesn't address pupil performance over time but only the final statement. Pupil motivation is more external than internal. In our opinion, this type of evaluation isn't as effective as formative evaluation but it's also very important for personality development and informative function. Often this evaluation is only based on the average of all pupils' marks over a certain period of time - for example, half-yearly. Thoughtful formative evaluation should be added to the average of the marks so that pupils approach worse marks positively and their motivation continues to develop for further performance. This evaluation is often stressful for pupils and they may feel limited by the evaluation scale.

- Normative evaluation is a type of relative performance evaluation, where the benchmark is the very important criterion in which we perform this evaluation. The measure is a social norm established with respect to a particular pupil group or population [1].

\section{Self-Assessment}

Self-assessment, which is also sometimes called autonomous evaluation, based on the notion of autonomy, means functional independence and autonomy. The pupil should be led to own decision-making and self-expression of their feelings and opinions. Weimer [7] believes that the development of self-assessing skills is largely affected by a teacher's emphasis on making pupils aware of themselves and being responsible for the decision they make in learning. Before the teacher decides to use this evaluation in their class, they should answer the question whether they believe in it and want to improve it. They should also realise that pupils won't be under their "wings" forever, and it's very important to learn how to evaluate themselves and clarify their opinions for an individual pupil and their future independent life. The possibility of evaluating and arguing their own work motivates pupils to further and perhaps even better performance or activity.

In order to give pupils the ability to self-assess, the teacher must prepare them step by step. Firstly, the teacher should provide pupils with information that making a mistake at school isn't 
a reason to walk away with the head down but to perceive it positively as it can help them in other activities. It's important to be able to work with mistakes. Čechová [7] highlights the reasons for the development of pupils' self-assessment and I think that every teacher should know, and be aware of them in case of introducing pupil self-assessment. These are the reasons:

- We make the pupil co-responsible for their own development.

- Self-evaluation skills lead to the development of personality.

- Self-assessment does not harm the self-concept of pupils, it does not harm them.

- Self-assessment has individual validity, thanks to which evaluation of every pupil in the classroom can take place.

- Pupils can also use the self-assessment skills in life outside of school.

\section{Methodology}

The presented research is part of a wider research survey. The first step was a qualitative study that aimed at understanding teachers better as well as their views on the current use of assessment in primary education. The second step was the quantitative study [8], which aims to provide a more objective view of the examined problem and the possibility of generalising the data obtained.

\section{Research Goals and Research Issues}

The main aim of the thesis is to discover which types and forms of evaluation are used in primary schools. The partial objective was to find the reasons for the most commonly used evaluation methods. Last but not least, we dealt with the issue of advantages and disadvantages of individual forms of evaluation seen by primary school teachers. A quantitative approach has been chosen to meet the research goals, as it's an attempt to describe the chosen phenomenon.

\section{Research Method}

In view of the purpose of the thesis, the questionnaire survey method [9] was chosen. On the basis of the previous qualitative survey results, a questionnaire of our own construction was compiled and its validity was ensured by a pre-survey carried out on a group of ten respondents. Subsequently, the selected questions were modified and then the data was collected.

The questionnaire consists of five identification questions that identify the respondents' gender, length of practice, school type, class in which they are currently teaching and municipality size. Then there are nineteen closed, open, scaling and test questions.

With regard to the requirement of gaining a larger amount of data, a combination of personal and electronic administration was chosen when a form was created in Google Forms, which was subsequently administered in primary schools throughout the Hradec Kralove and Pardubice regions of the Czech Republic.

\section{Research Sample}

A total of 115 respondents were surveyed. The average length of practice is 20 years. From the selection viewpoint, a randomised stratified selection was chosen, with the criterion being the school's location- a municipality of over 5,000 inhabitants, a municipality between 10,000 and 50,000 inhabitants and the municipality of up to 5,000 inhabitants. A total of 173 questionnaires were administrated, 115 were processed and the return was $66.4 \%$, which we consider to be a satisfactory quantity. Data collection took place in March 2018. 


\section{Selected Research Results}

During the questionnaire survey we first asked the respondents what forms of evaluation they prefer in their pedagogical practice (see Table 1).

Table 1. Preferred evaluation style

\begin{tabular}{|l|c|c|}
\hline & Frequency & $\%$ \\
\hline Marking & 73 & 63.5 \\
\hline $\begin{array}{l}\text { Graphic review (pictures, } \\
\text { smiles, stamps ...) }\end{array}$ & 25 & 21.7 \\
\hline Verbal evaluation & 14 & 12.2 \\
\hline Other & 3 & 2.6 \\
\hline
\end{tabular}

The most preferred form of assessment is marking and this was expected. Marking is really the most widely used form of evaluation in primary schools. In our opinion, this is a form that both pupils and parents require, and it's a proven way for teachers to evaluate pupils according to their criteria. However, it's important to add that teachers should add a lot of other verbal or non-verbal activities to the markings. The option "other" was a combination of all the evaluation styles listed, so it's not any kind of new form.

Subsequently, in response to the previous question, we asked the respondents why they're evaluating in that way (see Table 2).

Table 2. Reasons for using marks

\begin{tabular}{|l|c|c|}
\hline & Frequency & $\%$ \\
\hline Unambiguousness & 39 & 33.9 \\
\hline Intelligibility & 26 & 22.6 \\
\hline Speed & 15 & 13.0 \\
\hline It suits the teacher & 14 & 12.2 \\
\hline It's proven over time & 13 & 11.3 \\
\hline Clear arrangement & 8 & 7.0 \\
\hline
\end{tabular}

Despite the fact that marking is still talked about as an unfortunate influence on the child's psyche, in our questionnaire survey this evaluation method is the most popular and most used. According to respondents, the main reasons include the unambiguousness of marks not only for teachers and pupils, but also for parents. This is closely related to the clarity of marks. In our opinion, because of the unambiguousness and comprehensibility of marks there isn't a frequent misunderstanding of pupils' performance. Speed and suitable style are the answers of other respondents and they obtained almost the same percentage of answers. Last but not least, the interviewees believe that marking also contains testimony and clarity. Since the mark evaluation has been introduced to schools for several years, it's likely to be the best way and not every teacher is interested in changing their stereotypical leadership in their teaching profession.

In order to decipher the preferred evaluation styles, we also asked what the reasons for using verbal evaluation (see Table 3). 
Table 3. Reasons for using verbal evaluation

\begin{tabular}{|l|c|c|}
\hline & Frequency & $\%$ \\
\hline Intelligibility & 29 & 25.2 \\
\hline $\begin{array}{l}\text { It's better to describe the } \\
\text { pupil's specific progress }\end{array}$ & 29 & 25.2 \\
\hline Better motivation & 20 & 17.4 \\
\hline It suits the teacher & 20 & 17.4 \\
\hline $\begin{array}{l}\text { It isn't possible to express } \\
\text { everything with a mark }\end{array}$ & 17 & 18.8 \\
\hline
\end{tabular}

We have mentioned several times that verbal evaluation is becoming a growing trend in Czech education and therefore we were very interested in how many respondents tend to this trend. Each of them was free to comment on why they liked or preferred this evaluation method, and from these responses we created the categorisation of the repeated responses. The most common reason for the preferring this style is the clarity and more specific description of the pupil's progress. Both of these responses were reported by $25 \%$ and repeated more frequently. Verbal evaluation has many advantages as well as drawbacks according to many researches, and clarity is one of the major advantages of this form of evaluation. Describing how well a pupil should work for their improvement is of course very important, but on the other hand, we believe that counselling or instructing a pupil on this path can even be done without verbal evaluation.

We have been more concerned with the evaluation of the educational process results from the teachers' viewpoint, it's also necessary to mention one of the current preferred trends in evaluation which is self-assessment (see Table 4)

Table 4. Reasons for using self-assessment

\begin{tabular}{|l|c|c|}
\hline & Frequency & $\%$ \\
\hline $\begin{array}{l}\text { Ability to review your own } \\
\text { performance critically }\end{array}$ & 39 & 33.9 \\
\hline $\begin{array}{l}\text { Personality development of } \\
\text { pupils }\end{array}$ & 35 & 30.4 \\
\hline $\begin{array}{l}\text { Ability to find the causes of } \\
\text { failure and learn from them }\end{array}$ & 24 & 20.9 \\
\hline $\begin{array}{l}\text { Promoting social climate in } \\
\text { classroom }\end{array}$ & 17 & 14.8 \\
\hline
\end{tabular}

The teachers consider the ability to inspect their own performance critically and at the same time personality development of the pupil as the greatest benefit of self-assessment. Logically, these two most frequent items are linked because the ability of self-reflection has an impact on human personality development. From pedagogical point of view, it is work with a mistake, but it's also related to the development of a person, because when we can find the mistake and learn from it, de facto we learn by that and personally mature. 


\section{Summary}

The results of our research show that in Czech schools, the quantitative evaluation style in the form of classification is still the most prevalent. Several reasons are identifiable. First, the tradition in the Czech socio-cultural environment, then the clarity, the comprehensibility and the uniqueness of marks. This contributes to promoting the evaluation objectivity, which is the most frequently mentioned requirement for school evaluation in the long term.

However, at the same time, teachers realise that quantitative evaluation isn't capable of affecting individual development, therefore they are increasingly using a combination of qualitative evaluation and especially verbal evaluation. In this context, they mainly use a formative type of evaluation that encourages pupils' internal motivation to study further and is a stepping stone to the development of pupils' personality.

This is also related to the development of self-assessment as one of the elements of greater involvement of pupils in the implementation and evaluation of school results. At the same time, self-evaluation is perceived as a means of personal development of pupils based on the ability to critically evaluate their own performance and to learn to work positively with a mistake as with the way to learn something new not only from the knowledge or skills point of view, but also from the point of view of learning oneself.

\section{Acknowledgement}

This research was financially supported by a specific research project for the Faculty of Education, University of Hradec Králové in 2018 Types of evaluation at primary school level from the teachers' point of view.

\section{References}

[1] J. Slavík, Hodnocení v současné škole [Assessment in contemporary school], Portál, Praha, 1999.

[2] J. Čáp, J. Mareš, Psychologie pro učitele [Psychology for teachers], Portál, Praha, 2001.

[3] J. Průcha, Pedagogická evaluace [Pedagogical evaluation], Masarykova univerzita, Brno, 1996

[4] Z. Koláŕ, R. Šikulová, Hodnocení žáků [Evaluation of pupils], Grada, Praha, 2009.

[5] G. Petty, Teaching today, Nelson Thornes, 2009.

[6] K. Starý, V. Laufková, Formativní hodnocení ve výuce [Formative assessment in education], Portál, Praha, 2016

[7] M. Weimer, Learner-centered teaching - Five key changes to practice, Jossey-Bass,San Francisco, 2013

[8] J.W. Cresswell, Research design: qualitative, quantitative, and mixed methods approaches, SAGE, Los Angeles, 2014.

[9] S. Gorard, Quantitative Methods in Educational Research, Continuum, London, 2001. 